\title{
REGULAÇÃO GOVERNAMENTAL EM TEMPOS DE CRISE NO SEGMENTO PRIVADO DO ENSINO SUPERIOR BRASILEIRO
}

http://dx.doi.org/10.5902/2318133863427

\author{
Thiago Henrique Almino Francisco ${ }^{1}$ \\ Pedro Antonio de Melo² \\ Migulangelo Gianezini, ${ }^{3}$ \\ Leticia da Silva Cinha ${ }^{4}$
}

\begin{abstract}
Resumo
Neste artigo tem-se como objetivo de discutir os impactos dos movimentos regulatórios nas IES brasileiras a partir do panorama apesentado nos atos regulatórios publicados desde o início da pandemia covid-19 no Brasil. Por meio de uma análise documental, considerando portarias, pareceres e medidas provisórias publicadas desde março de 2020, buscou-se compreender a dinâmica regulatória neste período de crise e o papel de cada entidade neste processo. Ao analisar os dados as categorias de análise foram concebidas a partir da análise de conteúdo e ofereceram condições para compreender o movimento que impactou o ensino superior brasileiro. Os resultados demonstram que o papel do Conselho Nacional da Educação foi essencial para a prototipação do modelo brasileiro de ensino mediado por tecnologias.

Palavras-chave: regulação; ensino superior; gestão universitária.
\end{abstract}

\section{GOVERNMENT REGULATION IN TIMES OF CRISIS IN THE PRIVATE SEGMENT OF BRAZILIAN HIGHER EDUCATION}

Abstract

This article aims to discuss the impacts of regulatory movements in Brazilian HEls from the perspective presented in the regulatory acts published since the beginning of the pandemic in Brazil. Through a documentary analysis, considering ordinances, opinions and provisional measures published since March 2020, we sought to understand the regulatory dynamics in this period of crisis and the role of each entity in this process. When analyzing the data, the analysis categories were conceived from the "content analysis" offered conditions to understand the movement that affected Brazilian higher education. The results demonstrate that the role of the National Education Council was essential for the prototyping of the Brazilian model of teaching mediated by technologies.

Key-words: regulation; higher education; university management.

\footnotetext{
1 Universidade do Extremo Sul Catarinense, Brasil. E-mail: proftf@gmail.com.

2 Universidade Federal de Santa Catarina, Brasil. E-mail: pedro.inpeau@gmail.com.

3 Universidade do Extremo Sul Catarinense, Brasil. E-mail: miguelangelo@unesc.net.

4 Universidade do Extremo Sul Catarinense, Brasil. E-mail: leticiaaacunha@gmail.com. 


\section{Introdução}

$\mathrm{O}$ ano de 2020 foi um momento de reflexão a respeito da governança jurídicoadministrativa no contexto educacional, ocasionada pelas interferência da pandemia covid-19 na sociedade mundial. Os impactos foram severos em diversos segmentos econômicos da sociedade, o que levantou um conjunto de desafios urgentes, descortinando lacunas importantes no segmento. Em específico no contexto do ensino superior o ambiente regulatório foi impactado em função da ausência de diretrizes claras por parte dos órgãos reguladores do ensino superior brasileiro.

No que se refere à regulação, a experiência contemporânea no ensino superior brasileiro demonstra que esta prática ganhou contornos cada vez mais interdisciplinares, ampliando as oportunidades de discussão a respeito do tema. No contexto brasileiro, mais especificamente a partir de 2004, os estudos a respeito da articulação entre a avaliação da qualidade e a regulação tornam-se mais consistentes com o surgimento do Sistema Nacional de Avaliação do Ensino Superior - Sinaes. Além de uma forte estrutura regulatória articulada com um arcabouço normativo bastante consistente, o sistema prevê a participação estatal em diversos momentos do posicionamento das instituições, especialmente no segmento não estatal.

Vale ressaltar que a experiência educacional e universitária, no Brasil, tem um forte apelo regulatório, o que demonstra que o modelo contemporâneo ainda guarda muitas influências daqueles que estabeleceram o percurso educacional brasileiro. Portanto, estudar a relação entre a regulação e o período de excepcionalidade proporcionado pela pandemia covid-19 pode ampliar o debate sobre os desafios e as perspectivas da regulação para o segmento da educação superior no Brasil.

\section{O histórico do movimento regulatório na educação superior brasileira}

No contexto da gestão administrativa o conceito da regulação pode ser reconhecido como um indicativo de um fenômeno polissêmico, devido as diversas interpretações que pode possuir. No caso do ensino superior historicamente a regulação tem um movimento pautado em dois elementos: a participação do Estado no movimento expansionista do ensino superior e a integração com o processo de avaliação com o objetivo de instruir a sociedade à escolha pelas instituições mais aptas à atendê-la.

Um dos campos relevantes do contexto da gestão universitária é o da regulação. Imbricada em um contexto interdisciplinar, que considera a Administração, o Direito, a Sociologia e, até mesmo, a Pedagogia, a regulação é tratada como um conceito emergente na literatura em gestão universitária, sobretudo por se tratar de uma temática que tem relação direta com a perenidade das instituições. Por tal fato, compreendê-la, em seus conjuntos teóricos, metodológicos e históricos, proporciona fundamentos para sua aplicação, cuja operacionalidade é turbulenta em função das diversas e distintas interpretações de seus atos.

Os textos atuais que tratam do tema tem discutido o processo em torno dos resultados do Exame Nacional de Desempenho dos Estudantes - Enade -, tratando-o como elemento prescritivo, retirando da regulação uma importante condução preditiva. Especialmente a partir do surgimento do Sinaes, cuja concepção envolve a integração entre avaliação, regulação e supervisão, percebe-se a preocupação da comunidade científica sobre o tema da regulação, muito embora ele já esteja consolidado no histórico 
da educação superior brasileira. Os textos de Rangel (2012), Dantas (2013), Hora (2013), Queiroz (2014) destacam que o tema da regulação é singular no cenário da gestão universitária, especialmente pela sua condição de norteador das práticas de compliance que são definidas por Covac e Silva (2015) como elementos fundamentais da responsabilidade social de uma instituição de ensino superior.

Ainda sob este ponto de vista De Paula, Costa e Lima (2019) destacam que a prática da prestação de contas está ligada com o processo regulatório, já que ambos os exercícios proporcionam indicações gerenciais e orientam a participação do Estado no processo de gestão e desenvolvimento de instituições de ensino superior. A visão de Pereira, Araujo e Machado-Taylor (2020) segue nessa perspectiva e atrela a relação entre os instrumentos de avaliação ao processo regulatório, indicando que este exercício é elementar à gestão.

Nesse sentido, a regulação se estrutura como indicativo de elemento estruturador da gestão na medida em que incorpora uma série de princípios que se constituíram ao longo de sua trajetória metodológica e estrutural no campo do ensino superior brasileiro. Em suas fases principais, retratadas por Queiroz (2014), o que se indica é a prática metodológica de intervenção estatal por meio de dispositivos normativos, prescritivos, que indicam elementos básicos para a orientação da atividade de instituições e ofertas de curso, proporcionando condições para que o estado possa microgerenciar as instituições de ensino superior. De acordo com a autora as fases da regulação aprimoraram a estrutura social de intervenção estatal do ensino superior, constituindo o modelo de referencia atual para a participação do estado na governança do ensino superior.

A fase um, denominada por Queiroz (2014) de era Vargas, foi a fase em que a experiência inicial em regulação do ensino superior se consolidou, instituindo os conceitos de equiparação que, por analogia, observava uma série de movimentos semelhantes aos atuais processos de credenciamento e recredenciamento institucional. Este período, que se iniciou a partir da Reforma Francisco Franco, teve início com a divulgação do primeiro marco legal que orientou o movimento expansionista das universidades, contribuindo para o desenvolvimento do segmento universitário no ensino superior brasileiro. Os primeiros decretos resgataram os movimentos iniciais do processo regulatório, já iniciados na época da implantação das escolas de ensino superior, por volta de 1889, e construíram o esquema operacional que orientou 0 modelo organizacional de ensino superior, bem como os papeis a serem exercidos pelo então Ministério da Educação e Saúde Pública. Criaram-se os institutos estatais que orientam as atividades de intervenção no processo expansionista, a exemplo do Conselho Nacional de Educação.

A segunda fase do processo, que de acordo com Queiroz (2014) se denominou de República populista, foi uma fase cujos registros da dicotomia público-privado ganharam certa notoriedade na medida em que o processo expansionista se desenvolveu com o apoio do fluxo regulatório normatizado, pelas vias do segmento não estatal, constituindo um corpus universitário no Brasil com características acadêmicas vinculadas a pesquisa e a um modelo educacional integral, interdependente da prática da investigação científica, com origens nas influências internacionais, sobretudo espanholas e francesas. Na época pelo menos cinco dispositivos normativos foram publicados com o objetivo de orientar 
atividades operacionais e curriculares nos cursos de graduação, cujas normas eram definidas pelo então Conselho Federal de Educação. Esta fase pode ser considerada uma fase de amadurecimento para o que se propôs na fase seguinte, que foi a da primeira Lei de Diretrizes e Bases da Educação.

Na terceira fase, denominada por Queiroz (2014) como a fase do Regime militar, foi a que trouxe um conjunto de inovações incrementais ao contexto e ao processo operacional de governança do ensino superior brasileiro. Num contexto influenciado pelo modelo não estatal, privado e centrado em instituições isoladas, foi neste período em que a primeira edição da LDB se instituiu. Nesta fase é que uma das grandes discussões atuais do ensino superior teve início e, quando surgiu por iniciativa da Capes, o processo de avaliação dos programas de pós-graduação strico sensu, que influenciou o processo de expansão e posicionamento da pesquisa no Brasil. Foi neste tempo que teve início uma discussão a respeito do processo avaliativo no ensino superior, que já estava referenciado nas contribuições de Tayler (1874) como sendo um mecanismo efetivo para proporcionar eficiência aos currículos e às operações institucionais. Registra-se que, em consonância com o Relatório de Atcon (Francisco, 2012), instituía-se a época o modelo representativo da concepção do ensino superior brasileiro, que emergiu nos anos de 1889 a partir dos esforços da livre iniciativa e de modelos institucionais isolados, sem as características universitárias. Foi um tempo de expansão e também da consolidação de operações que são análogas aos atuais processos regulatórios institucionais e de cursos.

Na quarta fase, denominada por Queiroz (2014) de Ensaios de políticas de avaliação e reprodução de marcos regulatórios, o que se destacou foram os esforços iniciais para a consolidação do primeiro sistema de avaliação do ensino superior brasileiro pelas vias do Paru e do Geres. Contudo, em virtude de interferências políticas, as quais também são citadas por Zandavalli (2009), ambas as tentativas não foram bem sucedidas. Neste período percebeu-se uma prática bastante incomum no histórico da governança do ensino superior brasileiro, na medida em que atos estatais impediram a abertura de novos cursos e instituições no ensino superior brasileiro. O ponto mais expressivo desta fase foi a publicação da Constituição Federal de 1988, que normatizou toda a estrutura educacional e delimitou as bases para todos os atos regulatórios aplicados aos sistemas federal, estaduais e municipais. Por meio de oito dispositivos normativos, no período de 1985 a 1990, instituíram-se pequenas alterações no corpus regulatório existente, as quais se ocuparam de aprimorar o controle ao processo de expansão, vagaroso em comparação aos outros períodos, sob a justificativa de controle e acompanhamento da qualidade que era considerada precária pelos reguladores da época.

$\mathrm{Na}$ fase seguinte, denominada pela autora de Reprodução de práticas regulatórias e inovação com programas de avaliação, que se estabeleceu entre os anos de 1992 e 1995, há o registro de um movimento conturbado do ponto de vista político, sobretudo em função do processo de impeachement do presidente Fernando Collor de Mello. Foi um momento distinto no contexto nacional pela influência de práticas que promoveram a abertura economia do país e ampliaram a competição e a competitividade no campo industrial brasileiro. No contexto do ensino superior neste período o principal destaque é para o Programa de Avaliação Institucional das Universidades Brasileiras - Paiub -, que tentou instituir um movimento avaliativo, na perspectiva formativa, integrando várias formas para articular a regulação e a avaliação institucional, mas que se esvaziou ao

\begin{tabular}{|l|l|l|l|l|l|}
\hline Regae: Rev. Gest. Aval. Educ. & Santa Maria & v. 10 & n. 19 & e63539, p. 1-15 & 2021 \\
\hline
\end{tabular}


longo do período em virtude da falta de apoio político-institucional e de adesão das universidades. No campo normativo destaca-se a lei n. 9.131, de 24 de novembro de 1995, que instituiu mecanismos de avaliação, mais especificamente no que se refere a avaliação dos estudantes.

Posteriormente, na fase que Queiroz (2014) denomina de Avaliação a serviço da regulação nacional, estabeleceu-se um movimento em torno do processo regulatório como indutor da qualificação na governança do ensino superior. Com a lei n. 9.131/1995 e o esvaziamento do Paiub, o Exame Nacional de Cursos foi o precursor de um recurso avaliativo de larga escala que tinha o objetivo de criar um panorama de qualidade do ensino superior. Pela metodologia escolhida para a avaliação um determinado conjunto de cursos, em um determinado período temporal, participaria de uma avaliação em que seus concluintes seriam perquiridos a respeito do conjunto de conteúdos previstos nos currículos mínimos, além do retorno de um movimento expansionista empreendido pelo segmento privado motivado, sobretudo, pela LDB e pela lei n. 9.870, de 23 de novembro de 1999. Por meio destes dois dispositivos, e de um conjunto de portarias e normas que ordenavam as operações de intervenção estatal na gestão universitária, foi possível identificar práticas de ranqueamento, expansão de cursos, vagas e instituições, tornando o contexto do ensino superior brasileiro eivado de complexidades. Esta fase perdurou até o ano de 2002, e se estabeleceu em torno de 18 instrumentos normativos.

A fase seguinte foi marcada por uma transposição no paradigma social brasileiro, em função de políticas públicas instituídas pelo governo do presidente Luiz Inácio Lula da Silva (2002 a 2010) e que seguiu até o final do governo de Michel Temer (2018). O que se identificou nesta fase foi a articulação entre a avaliação, a regulação e a supervisão do ensino superior proporcionada pelas diretrizes do Sinaes. Emergiu uma abordagem sistêmica, Ristoff e Guolo (2006), que gerou um conjunto de indicadores norteadores do processo regulatório que, em certo momento, também esvaziou a perspectiva avaliativa do Sinaes. De 2004 a 2018 o que se percebeu foi um movimento de intervenção estatal na dinâmica gerencial do ensino superior brasileiro, com a consolidação do processo de avaliação institucional in loco, das comissões assessoras e da participação do Inep como entidade vinculada ao processo avaliativo. $O$ resultado foi um conjunto estrutural de indicadores que valorizaram a fluência das diretrizes curriculares nacionais, enquanto as limitações estavam sob o processo de gestão do Plano Nacional da Educação e das políticas de financiamento estudantil que também marcaram o período.

$\mathrm{Na}$ regulação das fases o que se percebe é uma prática norteadora da intervenção estatal no ensino superior, que indica critérios, padrões e elementos técnicos que devem se aplicar ao desenvolvimento de referenciais mínimos e elementares ao processo de gestão no ensino superior. Percebe-se que o movimento regulatório é uma constante no ensino superior brasileiro, que historicamente proporcionou um movimento bastante integrado com o Estado com o objetivo de influenciar a governança de instituições e cursos no ensino superior brasileiro.

\section{O Sinaes e a intersecção entre a regulação e a avaliação institucional}

O surgimento do Sinaes foi um marco contemporâneo do ensino superior brasileiro, mais especificamente no que se refere aos aspectos de governança que se aplicam às instituições de ensino superior. Em sua estrutura, Ristoff e Giolo (2006), havia um 
movimento sistêmico que buscava a integração de diversas esferas avaliativas no intuito de estabelecer condições de qualidade que pudesse retratar a identidade das instituições que se posicionam no complexo ambiente do ensino superior brasileiro. Na sua estrutura o que se destacou foi a integração proposta entre a avaliação, a regulação e a supervisão do ensino superior, consolidando um movimento eivado de complexidade na medida em que burocratizou a gestão do ensino superior brasileiro.

Tal burocracia se constituiu pelo fluxo de instrumentos legais que passaram a regular o sistema, torando-o complexo do ponto de vista de gestão e, muitas vezes, lento no que se refere à decisões estratégicas e gerenciais. Nesse sentido surgiram atividades que chamam a atenção pelo arcabouço técnico e pelas especificidades que envolviam o processo avaliativo. O Sinaes, na sua concepção, articulava diversos momentos avaliativos com foco em distintos aspectos, tendo como um dos objetivos precípuos a consolidação de princípios norteadores do sistema Francisco et.al. (2012). Contudo, não foi o que se percebeu na operacionalização do sistema e a participação estatal tornou-se legítima pelas vias do CPC, considerado um indicador marginal ao sistema de avaliação.

Os estudos em avaliação e regulação do ensino superior apresentam um crescimento quase que exponencial no período em que surgiu o Sinaes como sistema articulador entre a avaliação, a regulação e a supervisão da educação superior brasileiro. O trabalho de Francisco (2017) faz um registro do ponto de vista sistemático e destaca que a regulação tem ganhado contornos gerenciais a medida em que a regulação ganhou notoriedade como instrumento de gestão das instituições de ensino superior. Isso ocorreu em função da mudança de paradigma no sistema, que ocorreu em 2008 com a publicação da portaria normativa n. 08, de 05 de agosto de 2008, que instituiu o Conceito Preliminar de Curso - CPC.

A partir do CPC houve alterações na dinâmica do Sinaes em função da transposição do valor para a avaliação do estudante, proveniente dos resultados do Enade. Até ali consideravam-se os alinhamentos sistêmicos propostos por Ristoff e Giolo (2006) em que a auto-avaliação era a principal precursora do sistema. Em função das limitações operacionais dos órgãos reguladores e dos dispositivos que introduziram a dinâmica dos indicadores, tais como a portaria normativa n. 40, de 13 de dezembro de 2007, os indicadores passaram a influenciar a governança de instituições de ensino superior, especialmente em função da participação estatal por meio dos processos avaliativos.

A previsão da participação estatal se insere na gênese do sistema, na medida em que existe, na lei que criou o Sinaes, a previsão da participação das comissões de especialistas, em que os resultados do processo avaliativo seriam tomados como elementos norteadores do processo regulatório, como forma de cumprir os princípios estabelecidos na concepção do sistema. Por um lado, considerando o estudo de Francisco et. al. (2012), esse movimento de participação estatal, por meio da avaliação, contribuiria para a implantação e consolidação de princípios estruturantes do sistema, mas por outro lado emergia uma nova discussão a respeito da integridade do processo e dos vieses que se constituiriam em função da pouca experiência de alguns avaliadores.

Isso se potencializou na medida em que o CPC começou a ordenar as ações estratégicas institucionais de maneira que o Enade passou a ganhar notoriedade nos sistemas de governança das instituições. Tozzi e Tozzi (2016) salientam este aspecto evidenciando que o CPC substitui quase que integralmente a lógica da avaliação da 
qualidade por uma lógica pautada na regulação das atividades acadêmicas, especialmente pelo fato de que seus resultados interferem, diretamente, nas ações estratégicas institucionais.

Lacerda e Ferri (2017) destacam que o CPC surgiu como um indicativo responsável por proporcionar transposições importantes no cenário da avaliação, minimizando uma questão sistêmica prevista pelo Sinaes e instituindo um cenário de intervenção estatal, sobretudo em instituições sem autonomia, que se estabeleceria em torno de apenas um movimento considerado parte do sistema avaliativo. Os autores, assim como boa parte da literatura contemporânea que trata da avaliação do ensino superior, apresentam criticas ao CPC na medida em que o indicador não considera, pelo menos de forma direta, as particularidades da identidade institucional, ora materializada nos PDIs das instituições que se credenciaram nos mais distintos modelos e categorias administrativas. O CPC, portanto, restringiu o processo avaliativo num indicador com fins de regulação, de modo a orientar a participação estatal nos processos de reconhecimento, renovação de reconhecimento e de recredenciamento institucional.

Outra corrente, Francisco, Vefago e Melo (2020), discutem o CPC como um instrumento de governança que pode ser estratégico na medida em que se compreende 0 movimento proposto pelo Enade. Para além de uma prova o Enade se configura como um importante cockpit para a análise dos projetos pedagógicos de curso na medida em que oferece, por meio dos diversos indicativos provenientes do Inep, um conjunto de informações relevantes para decisões pedagógicas e administrativas no âmbito de cursos e instituições. Isso contribui para que seja possível direcionar, de forma estratégica, o movimento dos cursos de graduação que buscam se posicionar como aderentes às suas diretrizes curriculares nacionais.

Independente do viés o que houve de fato foi um movimento de participação estatal na governança das instituições e de cursos de graduação. As notas técnicas, publicadas anualmente pelos despachos da Seres, demonstravam a imponência do CPC e do Índice Geral de Cursos Avaliados - IGC -, que, grosso modo, é a média dos CPCs de uma instituição, na medida em que apresentavam todo o fluxo regulatório proposto para a renovação dos atos de cursos e institucionais quando conceitos e índices eram menor do que três. Em consonância a estes dispositivos, em 2017 emergiu um conjunto de portarias e normativos que indicam um conjunto de ações interventoras nos contextos institucionais, com destaque para a portaria n. 315, 04 de abril de 2018, que apresentou os elementos relacionados com os atos de supervisão.

A partir da experiência contemporânea do Sinaes o que se percebe é que o fluxo avaliativo foi subsumido por movimento ancorado no Enade e que diminuiu a importância da auto-avaliação e tornou os demais atos avaliativos imbricados com o processo regulatório, movimentado por um arcabouço legal e normativo. A participação do Estado, portanto, se configurou na medida em que os desempenhos nas avaliações dos estudantes ficam aquém do esperado, abaixo de três, e indicam movimentos de relação com o Estado que são articulados instancias reguladoras responsáveis por diversas indicações legais no ensino superior brasileiro. 


\section{A regulação em tempos de pandemia}

Com a portaria n. 343, de 17 de março de 2020, ocorreu o que se denominou de substituição das aulas presenciais por atividades acadêmicas mediadas por recursos tecnológicos, com o objetivo de impedir prejuízos mais severos as questões relacionadas ao calendário acadêmico. Entretanto, supõe-se que pela dependência dos órgãos reguladores do ensino superior em todo o escopo de governança, uma expectativa emergiu do segmento, em especial do não estatal, por orientações mais concretas a respeito das diretrizes norteadoras das ações.

Contudo, parece não ter sido este o resultado das portarias n. 343 , de 17 , de março de 2020 e, tampouco, da portaria n. 345, de 17 de março de 2020, já que ambos os dispositivos levantaram algumas questões importantes e que ao longo de todo o tempo de pandemia foram objeto de discussões pelo segmento do ensino superior brasileiro.

O primeiro ponto a ser abordado neste texto é o fato de que a primeira discussão do período de pandemia foi a relação entre a educação a distância e o ensino mediado por tecnologias que foi proposto pela portaria n. 343, de 17 de março de 2020, e por suas atualizações. Um ponto importante é destacar o artigo primeiro:

Art. 1 Autorizar, em caráter excepcional, a substituição das disciplinas presenciais, em andamento, por aulas que utilizem meios e tecnologias de informação e comunicação, nos limites estabelecidos pela legislação em vigor, por instituição de educação superior integrante do sistema federal de ensino, de que trata o art. $2^{\circ}$ do Decreto $\mathrm{n}^{\circ}$ 9.235, de 15 de dezembro de 2017. (Portaria n. 343, de 17 de março de 2020)

Ao ser publicada emergiu uma discussão em torno de dois elementos essenciais. $O$ primeiro deles relacionado ao enquadramento da proposta prevista na portaria, que seria análoga às atividades do ensino a distância e a segunda relativa ao computo das atividades para o percentual de $40 \%$ das atividades em EAD previstas para cursos presenciais determinadas pela portaria n. 2.117, de 06 de dezembro de 2019. Em ambos os casos percebe-se que houve uma demanda importante para os órgãos reguladores na medida em que modelos institucionais sem autonomia se viram no caminho para a oferta de atividades que utilizariam recursos, metodologias e processos relacionados a educação a distância. Havia, portanto, a necessidade de se propor uma experiência nesta nova perspectiva que deveria ser regulada pelos órgãos responsáveis por este processo no ensino superior. O que se identificou é que isso não aconteceu e as instituições sem a expertise para a atuação no ensino a distância precisaram definir suas experiências de forma autônoma, com um sentimento de dependência do MEC e da Secretaria de Regulação e Supervisão do Ensino Superior.

Emergiram dois sentimentos. O primeiro deles foi de um empoderamento das instituições isoladas de ensino superior, buscando a construção de experiências significativas e de inovações pedagógicas apropriadas aos seus currículos. A segunda foi uma insegurança, especialmente do ponto de vista regulador, em virtude da falta de parâmetros claros para as decisões acadêmicas e administrativas que se aplicassem a esse novo contexto pedagógico.

Outra situação está relacionada com a restrição aos estágios, imposta pela portaria n. 343 , de 17 de março de 2020: 
Art. 1 Autorizar, em caráter excepcional, a substituição das disciplinas presenciais, em andamento, por aulas que utilizem meios e tecnologias de informação e comunicação, nos limites estabelecidos pela legislação em vigor, por instituição de educação superior integrante do sistema federal de ensino, de que trata o art. 20 do Decreto ํㅜ 9.235, de 15 de dezembro de 2017. [...] § 3ํㅜ Fica vedada a aplicação da substituição de que trata o caput aos cursos de Medicina bem como às práticas profissionais de estágios e de laboratório dos demais cursos. (Portaria n. 343, de 17 de março de 2020)

Mesmo reestruturando a decisão na portaria n. 544, de 16 de junho de 2020, decorrente do parecer n. 05/2020, do Conselho Nacional da Educação, a Seres proporcionou impacto nas medidas administrativas de organização do calendário acadêmico das intuições. Ao restringir estágios e atividades práticas a Seres impediu o desenvolvimento de um conjunto de oportunidades importantes para que as IES pudessem inovar e criar alternativas sustentáveis para o desenvolvimento de currículos com práticas exitosas, tal como é previsto pelos instrumentos de avaliação propostos pelo Inep.

Outro ponto que trouxe embates do ponto de vista regulatório, considerando estágios e atividades práticas, estava no fato de que as portarias que antecederam a de n. 544. A restrição não encontrava lastro na medida provisória n. 927/2020, que autorizou as atividades de estágios de forma remota e regulamentou o trabalho mediado por tecnológica. Caso a portaria n. 343, de 17 de março de 2020 não fizesse essa restrição, as práticas estariam subordinadas as regulamentações regionais e, salvo o melhor juízo, proporcionariam condições importantes para que cursos e instituições pudessem inovar.

Outro elemento é significativo no intuito de orientar o processo regulatório das instituições de ensino superior. O que chama a atenção é o fato de que não foi o MEC o órgão responsável por organizar a minuta deste material, tampouco seu teor se tornou instrumento de qualquer tipo de dispositivo regulatório com a legitimidade do Ministério. A medida provisória n. 934/2020 foi um documento que proporcionou ainda mais flexibilidade na gestão dos calendários acadêmicos por parte das instituições, permitindo com que fosse possível criar alternativas para gerenciar as contingencias geradas pelos períodos de isolamento e distanciamento social que, em alguns Estados do Brasil, chegaram até mesmo a proporcionar lockdowns.

Além de flexibilizar dispositivos previstos na LDB, considerando os dias letivos, a medida provisória indicou condições para que as IES pudessem criar dispositivos que previssem revisões do percentual de frequência dos estudantes, já que a LDB não estabelece a obrigatoriedade do percentual de frequência, mas sim a existência dela. Por tal fato, ao estabelecer que as IES devem cumprir os 200 dias letivos, considerando as experiências mediadas por tecnologia, a medida provisória indica que é fundamental que a carga horária prevista nos PPCs sejam cumpridas, permitindo também que as IES criem formas autônomas de gerenciar seus respectivos processos pedagógicos. Dessa forma, a medida provisória indica, entre outros aspectos, a admissão das aulas não presenciais como instrumentos legítimos de cumprimento da carga horária. 
Outro ponto foi o que constou no texto em relação a conclusão do curso de estudantes matriculados em cursos na área da saúde. Para os acadêmicos matriculados no último período dos cursos de Medicina, Enfermagem, Farmácia, Fisioterapia e Odontologia a medida provisória proporcionou a condição da conclusão do curso com o aproveitamento mínimo de $75 \%$ da carga horária dos cursos e, no caso da Medicina, a conclusão de pelo menos $75 \%$ do internato. A priori isso pareceu uma prática eficiente para proporcionar condições de aumentar o contingente de profissionais aptos ao combate da pandemia, mas do ponto de vista do compliance isso foi um movimento bastante questionável por dois aspectos. $O$ primeiro pelo fato de que a medida provisória proporcionaria acesso ao mercado de trabalho de estudantes com possíveis lapsos de competências em áreas essenciais para as suas atividades, e o segundo ponto estaria relacionado ao impacto na sustentabilidade financeira de muitas IES que atuam nesta área e que tem, nos períodos finais de curso, um ticket médio mais elevado em função das especificidades de cada currículo.

Ao analisar todos estes elementos que impactam o fluxo regulatório das instituições de ensino superior brasileiras, é possível perceber as seguintes indicações:

a) Do ponto de vista do processo regulatório, desde o surgimento do Sinaes o contexto do ensino superior não estatal foi marcado por uma dependência regulatória das IES por parte do MEC, em que os órgãos reguladores executivos proporcionaram, de forma impositiva, as condições objetivas para as atividades operacionais no ensino superior;

b) No que se refere ao papel dos órgãos deliberativos foi possível identificar que, com exceção do Conselho Nacional da Educação, os demais institutos responsáveis pela avaliação, pela regulação e pela supervisão do ensino superior praticamente não se manifestaram objetivamente em torno da regulação do ensino superior. Em se tratando da Conaes, por exemplo, percebe-se que a última reunião ocorreu em 2019, tal como registros do endereço eletrônico da Comissão, e o Inep não se manifestou a respeito.

Para além das questões político-institucionais o que se percebeu, especialmente pelo parecer n. 05 de 2020, foi o papel do Conselho Nacional da Educação como propositor de medidas operacionais para as atividades acadêmicas no ensino superior, o que talvez indique um novo marco histórico na regulação do ensino superior brasileiro.

\section{O papel das entidades regulatórias do ensino superior}

Desde o período pós-constitucional o ensino superior brasileiro se estabeleceu como um segmento educacional complexo em virtude de seu tamanho, da distinção dos seus modelos e da pouca convergência de objetivos. Pode-se dizer que em função dos desdobramentos da Constituição Federal (Brasil, 1988), mais especificamente em função do art. 209, foi possível perceber um significativo aumento no quantitativo de estudantes, cursos, alunos e modelos institucionais. Por meio da lei n. 9.870, de 23 de novembro de 1999, em paralelo aos efeitos da lei n. 9.394, de 20 de dezembro de 1996, emergiu o segmento não estatal do ensino superior como mecanismo que alterou o contexto educacional brasileiro. À reboque de tudo isso surgiu um conjunto normativo complexo que foi aplicado ao acompanhamento e controle do processo de expansão e posicionamento de empreendimentos dessa natureza na sociedade brasileira. 
Nesse sentido, emergiram instâncias de decisão regulatória com o objetivo de proporcionar diretrizes operacionais para essas entidades, contribuindo para que a atuação destas instituições possa ocorrer dentro de princípios que sejam aderentes às necessidades e objetivos da própria sociedade. Ao longo do tempo, deste o surgimento do ensino superior no Brasil, percebe-se que essa é uma prática bastante comum, o que leva, por indução, a compreensão de que a relação entre o ensino superior e o Estado, desde a concepção deste modelo educacional, é bastante convergente. Não cabe aqui explorar profundamente cada entidade regulatória existente no contexto atual, mas sim destacar que, pelo menos desde 1930, essa prática está estabelecida no País com a participação ativa do Ministério da Educação e de outras autarquias ligadas a esta entidade.

Do ponto de vista dos impactos, especificamente no contexto recente do Sinaes, a Seres sempre foi considerada, no segmento não estatal do ensino superior, como um dos principais órgão responsáveis pelos ritos regulatórios mais específicos aplicados ao segmento, já que assumiu parte importante da responsabilidade de encaminhar as questões operacionais mais relevantes para a implementação do Sinaes. No caso do CNE sua função deliberativa e consultiva fez do Conselho uma entidade sem muita expressividade do ponto de vista regulatório, já que as decisões compartilhadas, muitas vezes, requeriam a homologação do Ministério da Educação. Muito embora, na essência, as entidades tenham finalidades diferentes, é correto afirmar que ambas exerceram, pelo menos durante o período recente de implementação do Sinaes, uma forte influência do ponto de vista regulatório nas IES brasileiras.

Não foi o que se percebeu no contexto da pandemia do Corona vírus no Brasil, já que as atividades educacionais foram impactadas assim que a União decretou o estado de calamidade pública. Na sequencia da publicação o que se esperou foram posicionamentos do ponto de vista regulatório, já que havia uma certa dependência das IES pelas decisões dos órgãos estatais. Houve, portanto, um momento de bastante insegurança jurídica e de poucas informações a respeito de como as IES poderiam resguardar suas atividades educacionais neste período.

Neste período, diferente de outros momentos em que a Seres estabelecia um conjunto de diretrizes regulatórias a partir do Ministério da Educação, o que se viu foi um pequeno protagonismo dessa entidade em questões essenciais que poderiam contribuir com o desenvolvimento dos projetos institucionais de contingência para a atuação no contexto da pandemia do novo Corona vírus. As IES, pelo menos desde março de 2020, sobretudo as que não possuíam autonomia ou credenciamento para o ensino a distância, aguardaram com expectativa um posicionamento que parece não ter ocorrido de forma clara. Surgiram, portanto, outros protagonistas.

A partir do parecer n. 05, de 28 de abril de 2020, homologado pelo Ministério da Educação em $1^{\circ}$ de junho de 2020, o Conselho Nacional da Educação, por intermédio do Conselho Pleno, se manifestou no sentido de promover orientações objetivas que impactaram diretamente na estrutura regulatória e no desenvolvimento de planos de contingências pedagógicas que poderiam ser desenvolvidos para contribuir com as 
atividades acadêmicas nas IES brasileiras, e em outras entidades educacionais. $O$ parecer trouxe em seu bojo conceitual muitas dúvidas dos gestores de IES, as quais puderam ser dirimidas com ações claras para o pleno funcionamento das IES em tempos de pandemia.

Nas considerações finais do documento há o seguinte destaque:

Ao mesmo tempo cabe reiterar o disposto na LDB, e em diversas normas do CNE, sobre a necessidade de que as soluções a serem encontradas pelos sistemas e redes de ensino sejam realizadas em regime de colaboração, uma vez que muitas destas soluções envolverão ações conjuntas de todos os atores do sistema educacional local e nacional. Para que se possa ter um olhar para as oportunidades trazidas pela dificuldade do momento, recomenda-se um esforço dos gestores educacionais no sentido de que sejam criadas ou reforçadas plataformas públicas de ensino on-line, na medida do possível, que sirvam de referência não apenas para o desenvolvimento dos objetivos de aprendizagem em períodos de normalidade quanto em momentos de emergência como este. (Paracer no 5 , de 28 de abril de 2020, p. 23)

O CNE, portanto, se empoderou no sentido de consolidar diretrizes que proporcionassem segurança jurídica para as IES, regulando elementos como a oferta de atividades remotas como substituição as aulas presenciais, aproveitamento das atividades práticas e estágios adaptados e oferecidos de forma mediada por tecnologia, e questões relativas as avaliações e adaptações de aprendizagens. Em especial no item que trata da educação superior, há um capitulo específico que apresenta direcionamentos importantes para a gestão do processo de ensino e aprendizagem na educação superior.

Ao ensino superior são 18 recomendações que orientam as atividades práticas, as atividades de estágio, as avaliações e demais aspectos essenciais ao processo de ensino e aprendizagem que permitiram maior segurança as IES para o desenvolvimento do percurso formativo e de adaptações essenciais aos projetos pedagógicos que são desenvolvidos em uma determinada conjuntura.

Em linhas gerais, portanto, é possível identificar que CNE assumiu o protagonismo regulatório em tempos de excepcionalidade, cumprindo o papel de orientar as atividades educacionais do ponto de vista do ensino superior. No que se refere ao papel do MEC foi possível perceber que, por intermédio da Seres, poucas ações ou informações foram compartilhadas, o que causou insegurança jurídica para o segmento.

\section{Considerações finais}

O ensino superior brasileiro tem sido tema de pesquisas em uma séria de contextos, sobretudo após o surgimento do Sinaes como sistema que articula os processos de avaliação, regulação e supervisão. Em se tratando de regulação o histórico recente mostra o protagonismo dos órgãos reguladores no sentido de interferir, de forma direta, na dinâmica estrutural e de funcionamento de IES e cursos no país, estabelecendo uma dinâmica de governança específica para este segmento educacional.

A partir dos resultados das análises documentais realizadas foi possível identificar o protagonismo do Conselho Nacional da Educação no sentido de promover diretrizes operacionais para as atividades acadêmicas no ensino superior brasileiro. Em detrimento de uma atuação bastante inexpressiva da Seres, principal órgão regulador do segmento 
não estatal do ensino superior no Brasil, o CNE, com o parecer n. 05, de 28 de abril de 2020, proporcionou um conjunto de elementos essenciais para o desenvolvimento de ações acadêmicas empreendida pelas IES neste tempo de excepcionalidade.

Pode-se concluir que o parecer n. 05, de 28 de abril de 2020, homologado em 1으 de junho de 2020, foi um dos instrumentos esclarecedores promulgados neste tempo de excepcionalidade, pois proporcionou segurança jurídica para as atividades acadêmicas desenvolvidas no ensino superior. Sobretudo do ponto de vista das atividades práticas e estágios, o documento proporcionou um novo olhar para estes elementos e inseriu muitos cursos tradicionais em trilhas inovadoras de aprendizagem, com o auxilio das atividades mediadas por tecnologia. Ademais, o parecer também oportunizou a organização dos calendários acadêmicos e estabeleceu práticas e direcionamentos para o aproveitamento de estudos, contribuindo para a adaptação do percurso formativo dos estudantes.

\section{Referências}

BRASIL. Lei n. 9.131/1995, de 24 de novembro de 1995: Altera dispositivos da Lei no 4.024, de 20 de dezembro de 1961, e dá outras providências. Presidência da Republica. Casa Civil. Subchefia para Assuntos Jurídicos. Brasília. 1995.

BRASIL. Lei n. 9394, de 20 de dezembro de 1996: estabelece as Diretrizes e Bases da Educação Nacional. Presidência da Republica. Casa Civil. Subchefia para Assuntos Jurídicos. Brasília. 1996.

BRASIL. Lei n. 9.870, de 23 de novembro de 1999: dispõe sobre o valor total das anuidades escolares e dá outras providências. Brasília: MEC. 1999.

BRASIL. Parecer n. 05, de 28 de abril de 2020: reorganização do calendário escolar e da possibilidade de cômputo de atividades não presenciais para fins de cumprimento da carga horária mínima anual, em razão da pandemia da covid-19. Brasília: CNE, 2020.

BRASIL. Portaria n. 2.117, de 06 de dezembro de 2019: dispõe sobre a oferta de carga horária na modalidade de Ensino a Distância - EaD em cursos de graduação presenciais ofertados por Instituições de Educação Superior - IES pertencentes ao Sistema Federal de Ensino. Brasília: MEC, 2019.

BRASIL. Portaria n. 315, de 04 de abril de 2018: dispõe sobre os procedimentos de supervisão e monitoramento de instituições de educação superior integrantes do sistema federal de ensino e de cursos superiores de graduação e de pós-graduação lato sensu, nas modalidades presencial e a distância. Brasília: MEC, 2018.

BRASIL. Portaria No. 343, de 17 de março de 2020: dispõe sobre a substituição das aulas presenciais por aulas em meios digitais enquanto durar a situação de pandemia do Novo Coronavírus - covid-19. Brasília: MEC, 2020.

BRASIL. Portaria n. 345, de 17 de março de 2020: altera a portaria n. 343, de 17 de março de 2020. Brasília: MEC, 2020.

BRASIL. Portaria n. 544, de 16 de junho de 2020: dispõe sobre a substituição das aulas presenciais por aulas em meios digitais, enquanto durar a situação de pandemia do novo coronavírus - Covid-19, e revoga as portarias MEC n. 343, de 17 de março de 2020, n. 345, de 19 de março de 2020, e n. 473, de 12 de maio de 2020. Brasília: MEC, 2020.

BRASIL. Portaria normativa n. 40, de 12 de dezembro de 2007: institui o e-MEC, sistema eletrônico de fluxo de trabalho e gerenciamento de informações relativas aos processos de regulação da educação superior no sistema federal de educação. Brasília: Inep, 2014. 
BRASIL. Portaria normativa $n$. 04, de 05 de agosto de 2008: regulamenta a aplicação do conceito preliminar de cursos superiores, para fins dos processos de renovação de reconhecimento respectivos, no âmbito do ciclo avaliativo do Sistema Nacional de Avaliação da Educação Superior - Sinaes. Brasília: Inep, 2008.

DANTAS, Renata Perez. A consensualidade na educação superior. São Paulo: PUCSP, 2013. 119f. Dissertação (Mestrado em Direito). Pontifícia Universidade Católica de São Paulo.

DE LACERDA, Leo Lynce Valle; FERRI, Cássia. Conceito preliminar de curso: conceito único para uma realidade educacional múltipla. Estudos em Avaliação Educacional, São Paulo v. 28, n. 69, 2017, p. 748-772.

DE PAULA, Alisson Slider do Nascimento; COSTA, Frederico Jorge Ferreira; LIMA, Kátia Regina Rodrigues. Accountability e o mosaico da política de avaliação da educação superior brasileira. Revista de Gestão e Avaliação Educacional, Santa Maria v. 1, n. 1, 2019, p. 1-15.

BRASIL. Constituição federal de 1988. Brasília: Senado Federal, 1988.

FRANCISCO, Thiago Henrique Almino et al. A contribuição da avaliação in loco como fator de consolidação dos princípios estruturantes do SINAES. Avaliação: Revista da Avaliação da Educação Superior, Campinas. v. 17, n. 3, 2012, p. 851-876.

HORA, Paola Matos da. Sentidos e significados do Índice Geral de Cursos na regulação da qualidade da educação superior. Brasília: UNB, 2013. 242f. dissertação (Mestrado em Educação). Faculdade de Educação, Universidade de Brasília.

PEREIRA, Cleber Augusto; ARAÚJO, Joaquim Filipe Ferraz Esteves; MACHADOTAYLOR, Maria de Lourdes. Remendo novo em roupa velha? Sinaes de maturidade ou de saturação do modelo de avaliação do ensino superior brasileiro. Revista Brasileira de Educação, v. 25, e250020 2020, p. 01-28.

QUEIROZ, Kelli Consuêlo Almeida de Lima. Reconhecimento de cursos de graduação em instituições privadas no marco do Sinaes: avaliação, regulação e acomodação. Brasília: UNB, 2014. 314f. Tese (Doutorado em Educação). Faculdade de Educação da Universidade de Brasília.

RANGEL, Susana Salun. Educação superior: o papel da união e a garantia de qualidade do ensino. São Paulo: USP, 2012. 413f. Tese (Doutorado em Direito). Universidade de São Paulo.

RISTOFF, Dilvo; GIOLO, Jaime. O Sinaes como sistema. Revista Brasileira de PósGraduação, Brasília v. 3, n. 6, 2006, p. 01-21.

ROTHEN, José Carlos. A universidade brasileira na Reforma Francisco Campos de 1931. Revista Brasileira de História da Educação, Rio de Janeiro v. 8, n. 2 2008, p. 141160.

SILVA, Daniel Cavalcante; COVAC, José Roberto. Compliance como boa prática de gestão no ensino superior privado. São Paulo. Saraiva. 2015.

TOZZI, Marcos José; TOZZI, Adriana Regina. Conceito preliminar de curso (CPC) $x$ conceito do curso (CC): há coerência desses valores nos cursos de engenharia. CONGRESSO BRASILEIRO DE EDUCAÇÃO EM ENGENHARIA, 44, 2016. Anais ... Natal: Abenge, 2016.

ZANDAVALLI, Carla Bussato. Avaliação da educação superior no Brasil: os antecedentes históricos do Sinaes. Avaliação. Campinas/Sorocaba, v. 14, n. 2, 2009, p. 267-290. 
Thiago Henrique Almino Francisco é professor na Universidade do Extremo Sul Catarinense.

Orcid: https://orcid.org/0000-0002-6285-7742.

Endereço: Avenida Universitária, 2600 - 88806-000 - Criciúma - SC - Brasil.

E-mail: proftf@gmail.com.

Pedro Antonio de Melo é professor na Universidade Federal de Santa Catarina.

Orcid: https://orcid.org/0000-0001-7607-4303.

Endereço postal completo: UFSC - caixa postal 476 - 88040900 - Florianópolis - SC

- Brasil.

E-mail: pedro.inpeau@gmail.com.

Miguelangelo Gianezini é professor na Universidade do Extremo Sul Catarinense.

Orcid: https://orcid.org/0000-0002-0785-6034.

Endereço: Avenida Universitária, 2600 - 88806-000 - Criciúma - SC - Brasil.

E-mail: miguelangelo@unesc.net.

Leticia da Silva Cinha é estudante do curso de Administração da Universidade do Extremo Sul Catarinense.

Orcid: https://orcid.org/0000-0001-7073-0269.

Endereço: Avenida Universitária, 2600 - 88806-000 - Criciúma - SC - Brasil.

E-mail: leticiaaacunha@gmail.com.

Critérios de autoria: o texto é desdobramento de um projeto de pósdoutoramento desenvolvido por Thiago Henrique Almino Francisco, sob a supervisão do prof. Pedro Antônio de Melo. Com o auxílio de Leticia Cunha foram realizadas as revisões teóricas e a redação do manuscrito, que foi revisado pelo prof. Miguelangelo Gianezzini. Todos os autores realizaram a revisão final e validação do manuscrito.

Recebido em 11 de dezembro de 2020.

Aceito em 20 de abril de 2021.

cc) (i) $(9)$ 